\title{
FLEXURAL STRENGTH AND ADHESION OF ZIRCONIA-REINFORCED LITHIUM SILICATE GLASS CERAMIC TO RESIN CEMENT AFTER THERMO-MECHANICAL LOAD CYCLING
}

\author{
Tarek A. Soliman*
}

\begin{abstract}
Purpose: The aims of this study were to evaluate the flexural strength and adhesion of zirconiareinforced lithium silicate glass ceramic with those of lithium disilicate after applying a combined thermo-mechanical load cycling.

Materials and Methods: Zirconia-reinforced lithium silicate (vita suprinity; SV) and lithium disilicate glass ceramics (IPS e.max CAD; EM) were the materials used in this study. Specimens with the required dimensions for microtensile bond strength and flexural strength test were prepared and finished. The specimens were divided into two groups: control group that was stored in distilled water at $37^{\circ} \mathrm{C}$ for $24 \mathrm{~h}$ (without thermo-mechanical load cycling) and test group (with thermomechanical load cycling). A total of 3,500 thermal cycles and 250,000 mechanical loading cycles were performed. Microtensile bond strength and flexural strength of each material were evaluated before and after thermo-mechanical load cycling. Moreover, additional micromorphological analysis such as those involving scanning electron microscopy and surface roughness of the etched ceramic bonded surfaces were performed for qualitative analysis. Data were analyzed using independent t-tests between the two glass ceramic groups, and paired t-test was used to detect significance within each group with and without thermo-mechanical load cycling.
\end{abstract}

Results: The effect of thermo-mechanical load cycling on microtensile bond strength was statistically significant for both types of glass ceramics (EM and SV) $(\mathrm{P}<.001)$ and the most frequent failure type was mode I (adhesive failure between cement and ceramic type) with pronounced effect on EM (66.67\%) than on SV (40\%). Regarding thermo-mechanical load cycling effect on flexural strength, there was statically significant difference $(\mathrm{P}<.001)$ only for EM.

Conclusions: SV glass ceramic showed higher bonding values than EM glass ceramic only after thermo-mechanical load cycling. However, it provides higher flexural strength values either before or after thermo-mechanical load cycling than EM glass ceramic.

KEYWORDS: Aging, Bonding values, Flexural strength, Reinforced glass ceramic

*Lecturer of Dental Biomaterials, Dental Biomaterials Dept., Faculty of Dentistry, Mansoura University, Egypt. 


\section{INTRODUCTION}

The continuous advance in the field of ceramics is because of their enhanced esthetics, chemical stability, biocompatibility, and wear resistance. Therefore, the mechanical and optical properties of ceramics are important in the clinical selection of ceramic system. ${ }^{1}$ Recently, using CAD/CAM system is of a great concern in dentistry, it is used as a substitute to traditional manufacturing processes to achieve the esthetic requirements of prosthetic restoration. Advances in dental ceramic materials provide all-ceramic restorations with adequate fatigue resistance to increase the longevity of CAD/ CAM ceramics. ${ }^{2,3}$

IPS e.max CAD, which is considered a monolithic ceramic restoration, was launched by Ivoclar-Vivadent. It is a lithium disilicate ceramic restoration providing esthetics without demanding a veneering ceramic. Because of its superior physical properties, it can be used as a single crown and partial coverage restoration either in anterior or posterior areas. ${ }^{1,4}$ Recently, zirconiareinforced lithium silicate $\mathrm{CAD} / \mathrm{CAM}$ glass ceramics, which have fine grained, homogeneous structure, have been introduced to the market by VITA (Zahnfabrick, Bad Säckingen, Germany) for the construction of anterior and posterior crowns, inlays and onlays. It is composed of lithium silicate that incorporates $10 \mathrm{wt} \%$ zirconia. According to the manufacturer's claims, the presence of zirconia strengthens the ceramic structure by interrupting the crack propagation. The structure obtained after crystallization has been supposed to enhance its mechanical properties and satisfies the highest esthetic demands. ${ }^{5}$

Clinically, bonding values and mechanical properties of ceramic restoration may be affected by exposure to oral environments after cementation. Fatigue fracture is a form of failure that occurs in structures with microscopic cracks when subjected to dynamic and fluctuating stresses. ${ }^{6}$ Both thermal variations and cyclic fatigue are considered as factors that could affect their mechanical properties and bond strength at ceramic/resin cement interface. Accordingly, they could provide a more detailed understanding of clinical failures. ${ }^{7-9}$

Guarda et $\mathrm{al}^{10}$ evaluated the bond strength of lithium disilicate glass ceramics under two different conditions: thermocycling and mechanical cycling. In addition, Sato et $\mathrm{al}^{11}$ assessed the thermocycling effect on microtensile bond strength of zirconiareinforced lithium silicate ceramics. Therefore, the current study aimed to evaluate and compare the flexural strength and adhesion of two glass ceramics with different microstructures (zirconiareinforced lithium silicate and lithium disilicate glass ceramics) after applying a combined thermomechanical load cycling, which is considered the worst case scenario. Moreover, additional analysis such as those involving scanning electron microscopy and surface roughness of the etched ceramic bonded surfaces were performed for qualitative analysis. The suggested null hypotheses were as follows: (1) there is no significant difference between the adhesion values of different ceramics-cement combinations before and after the thermo-mechanical load cycling and (2) there is no significant difference between the flexural strength of the two glass ceramic materials before and after the thermo-mechanical load cycling.

\section{MATERIALS AND METHODS}

Zirconia-reinforced lithium silicate (SV) (Vita Suprinity, lot; 47554, VITA Zahnfabrik, Bad Säckingen, Germany) and lithium disilicate CAD/ CAM glass ceramics (EM) (IPS e.max CAD, lot no; S50627, Ivoclar Vivadent, Schaan, Lichtenstein) were used in this study.

\section{Microtensile bond strength assessment}

Four rectangular $\mathrm{CAD} / \mathrm{CAM}$ ceramic blocks (10 $\mathrm{mm} \times 7 \mathrm{~mm} \times 3 \mathrm{~mm}$ ) were cut from each material 
by using ISOMET (Techcut4, Allied, USA) in the precrystalline stage. Ceramic blocks dimensions was measured by a digital caliper (Mitutoyo Corporation, Tokyo, Japan). Different grit sizes (600 to 1200 grits) of silicone carbide papers were used to finish the bonded surfaces of ceramic specimens under copious water cooling followed by a 3-min ultrasonic cleaning in distilled water. The fullcrystalline stage for ceramic specimens was then completed using a programat P500 furnace (IvoclarVivadent, Schaan, Liechtenstein). Composite resin Tetric N ceram (Ivoclar-Vivadent, Schaan, Liechtenstein) shade A3 was then used to duplicate each CAD/CAM ceramic block using a silicone impression material mold (Express, 3M ESPE; St Paul, USA). Composite resin was incrementally (2 mm) applied into the mold until it was filled, and each layer was cured using a LED light (Elipar Freeligh 2, 3M ESPE, 1,226 mW/ $\left.\mathrm{cm}^{2}\right) .{ }^{12,13}$

The cut surfaces for both the CAD/CAM glass ceramics were etched using hydrofluoric acid for $20 \mathrm{~s}$ followed by washing under distilled water and then air-drying for $30 \mathrm{~s}$. A silane coupling agent (Monobond Plus, Ivoclar-Vivadent, Schaan, Liechtenstein) was applied using microbrush and allowed to dry for $1 \mathrm{~min}$, and then a second coat was applied. The composite resin blocks were bonded to the treated $\mathrm{CAD} / \mathrm{CAM}$ glass ceramic surface by using a dual-cured resin luting agent (Variolink $\mathrm{N}$, Ivoclar-Vivadent, Schaan, Liechtenstein) under 500-gm static load. . $^{12,13}$

Glass ceramic specimens were divided into two groups: control group (non-aged group) that was kept in distilled water at $37^{\circ} \mathrm{C}$ for $24 \mathrm{~h}$ with no thermo-mechanical load cycling and test group (aged group) exposed to thermo-mechanical load cycling. Thermal cycling (3,500 cycles) was performed in distilled water (SD Mechatronik Thermocycler, FT200, JULABO GmbH, Germany) between $5{ }^{\circ} \mathrm{C}$ and $55{ }^{\circ} \mathrm{C}$ (dwell time of $30 \mathrm{~s}$ ). For mechanical cycling, the same specimens were then subjected to cyclic fatigue on a universal testing machine (Instron Electropolus 3000, E 300, Instron, England) for 250,000 cycles with a load of $80 \mathrm{~N}$ at a frequency of 4 cycles/s in a wet environment prior to testing..$^{10,14}$

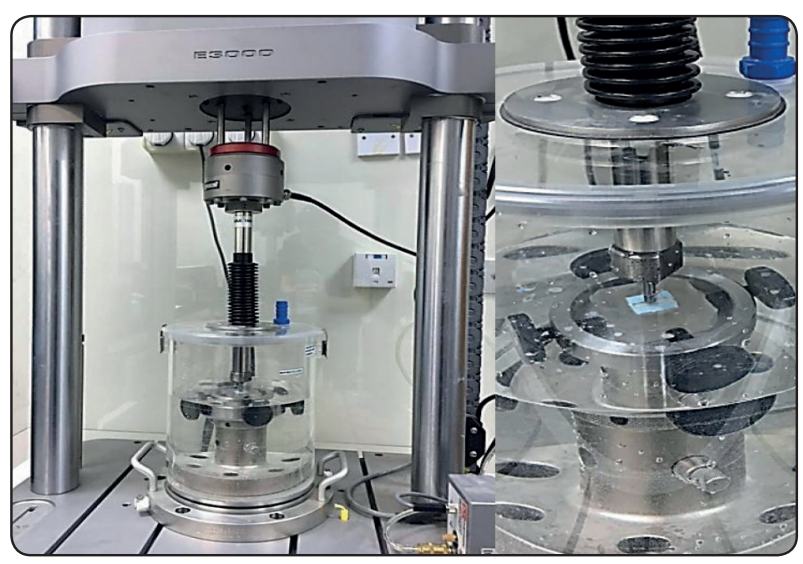

Fig. (1) Universal testing machine used for mechanical cyclic loading

The ceramic-composite blocks were then sectioned into beams ( $1 \pm 0.1$-mm thick). The peripheral beams were excluded because of the probability of deficient or excessive resin at the ceramic/composite interface, which might affect the results. A cyanoacrylate adhesive was then used to fix each beam to microtensile device grips. The microtensile bond strength test was conducted using a universal testing machine at a crosshead speed of $0.5 \mathrm{~mm} / \mathrm{min}$ until failure. The load at failure $(\mathrm{N})$ and the surface area $\left(\mathrm{mm}^{2}\right)$ for each beam were used to calculate $\mu \mathrm{TBS}$ in MPa. ${ }^{15,16}$ Optical microscope (Infinity 2, MEIJI Techno, EMZ-13 TRD, Japan) at 40x magnifications was used to check the debonded specimens. The mode of failure can be categorized as follows: type 1: adhesive failure at the ceramic/ resin interface, cohesive failure in the composite resin (type II) or ceramics (type III), or mixed failure (type IV). ${ }^{17}$

\section{Flexural strength assessment}

Twenty bar-shaped specimens $\left(18 \times 4 \times 3 \mathrm{~mm}^{3}\right)$ for each material were cut and randomly distributed into 
two groups: control group (non-aged) and test group (aged group), and the same thermo-mechanical load cycling process was applied as described before. Three point bending test was used to measure the flexural strength in a universal testing machine at a crosshead speed of $0.5 \mathrm{~mm} / \mathrm{min}$ until fracture according to ISO $6872 .{ }^{18,19}$ Flexural strength (MPa) was calculated using the following formula: FS (ó) $=3 \mathrm{~F}(\mathrm{~L}) / 2 \mathrm{wh} 2$, where $\mathrm{F}$ is the maximum load at the fracture point $\mathrm{N}, \mathrm{L}$ is the distance between the two supports $(\mathrm{mm})$, w is the specimen width $(\mathrm{mm})$, and $\mathrm{h}$ is the specimen thickness.

\section{Micromorphological analysis of etched ceramic surfaces}

Three representative specimens $(10 \mathrm{~mm} \times 10$ $\mathrm{mm} \times 1 \mathrm{~mm}$ ) from each ceramic were produced and polished using wet abrasive silica-carbide papers (grit No. 600, 1000, and 1200), cleaned with 96\% ethanol in an ultrasonic bath for $2 \mathrm{~min}$, and air-dried. Ceramic specimens were etched for $20 \mathrm{~s}$, mounted on metallic stubs, gold sputter-coated, and evaluated under a SEM (Quanta FEG 450, Amsterdam, Netherland) with original magnification range $2000-5000 \times$ for their qualitative analysis. ${ }^{20}$

Surface roughness of ten etched ceramic specimens for each material was characterized using a profilometer (Contour GT profilometer; BRUKER, RM1228, USA) that performed 2D surface roughness profile measurment in nanometer. Surface roughness $(\mathrm{Ra})$ for each specimen was recorded in nanometers $(\mathrm{nm})$ from three different sites, and the mean roughness ( $R a$ values) was then calculated. $^{21}$

\section{Statistical analysis}

All data were analyzed using SPSS software version 22 (SPSS Inc., Chicago, IL, USA), Independent t-test was used to detect significant difference between the two types of ceramics: without or with thermo-mechanical load cycling. Paired t-test was used to detect significant difference within the same ceramic material either without or with thermo-mechanical load cycling. Statistical significance was set at .05 probability level. The data were first verified by the Shapiro-Wilk test for the normal distribution of data.

\section{RESULTS}

Mean values and standard deviations of the microtensile bond strength are presented in table 1. The effect of thermo-mechanical cycling on microtensile bond strength was statistically significant for both the types of glass ceramics $\mathrm{P}<.001$. A statistically insignificant effect $(\mathrm{P}=.11)$ was detected between EM and SV glass ceramics when considering the overall microtensile bond strength values between the levels of independent variables (conditions with and without thermomechanical load cycling).

TABLE (1) Mean ( \pm standard deviations) microtensile bond strength values (Mpa) of EM and SV glass ceramics with or without thermomechanical load cycling

\begin{tabular}{|c|c|c|c|}
\hline \multirow{2}{*}{ Ceramic type } & \multicolumn{2}{|c|}{$\begin{array}{r}\text { Thermo-mechanical load } \\
\text { cycling conditions }\end{array}$} & \multirow{2}{*}{ Total } \\
\cline { 2 - 3 } & Without & With & \\
\hline EM $(\mathrm{X} \pm \mathrm{SD})$ & $33.12 \pm 1.38^{\mathrm{a}}$ & $20.79 \pm .86^{\mathrm{b}}$ & $26.95 \pm 6.42$ \\
\hline $\mathrm{SV}(\mathrm{X} \pm \mathrm{SD})$ & $31.13 \pm 1.57^{\mathrm{A}}$ & $27.79 \pm 1.06^{\mathrm{B}}$ & $29.46 \pm 2.156$ \\
\hline $\mathrm{P}$ value & $.008^{*}$ & $<.001^{*}$ & .11 \\
\hline
\end{tabular}

EM: E-max CAD lithium disilicate glass ceramic, $S V$ : suprinity; zirconia reinforced lithium silicate ceramic - Different superscript letters indicate significant difference between thermo-mechanical load cycling conditions for each glass ceramic $(P<.05)$.

- P value when comparing the two types of glass ceramics either overall or between each thermo-mechanical cycling conditions 


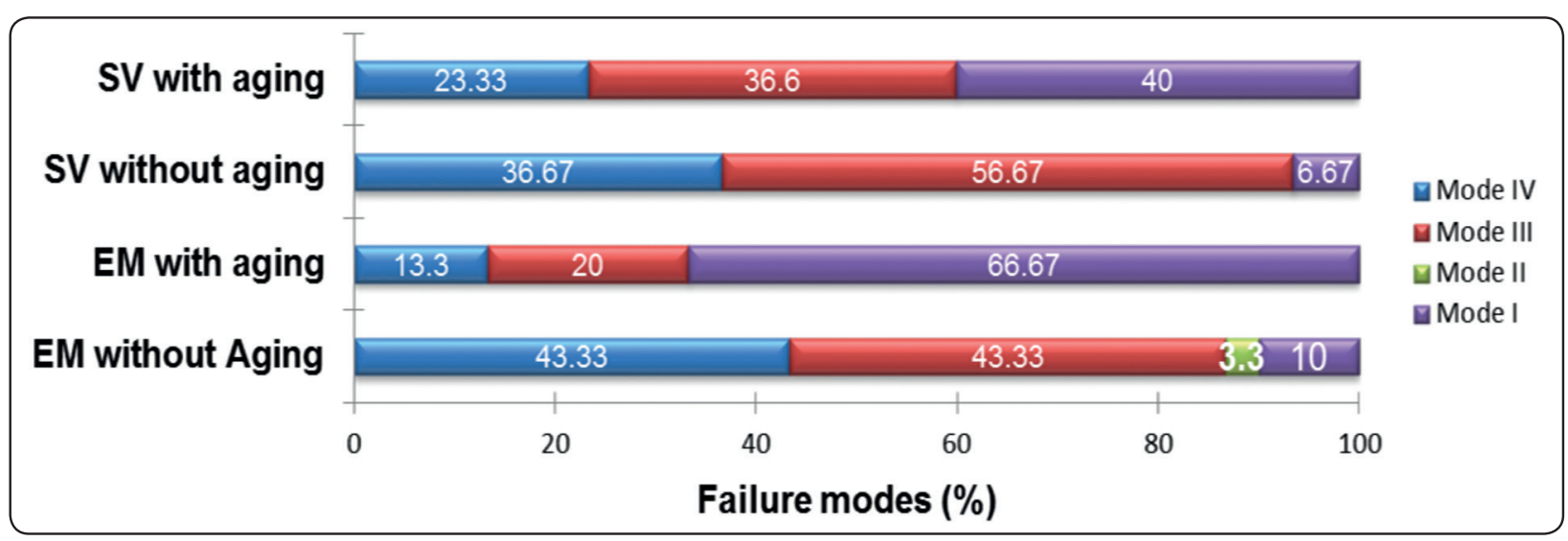

Fig. (2) Bond failure modes in each group

The percentages of different failure modes for each type of glass ceramic either with or without thermo-mechanical load cycling are shown in Figure 2. Regarding the effect of thermo-mechanical load cycling, the most frequent failure type was mode I (adhesive failure between resin cement and ceramic type) with pronounced effect on EM (66.67\%) than on SV glass ceramic (40\%).

Mean values and standard deviations of the flexural strength are presented inTable 2 . The effect of thermo-mechanical cycling on flexural strength was statistically significant only for EM glass ceramics $(\mathrm{P}<.001)$. Flexural strength of EM glass ceramics decreased significantly $(\mathrm{P}<.001)$, whereas that of SV glass ceramics insignificantly decreased $(\mathrm{P}=.07)$. Moreover, a statistically significant effect $(\mathrm{P}<.001)$ was detected between EM and SV ceramics when considering the overall flexural strength values between the levels of independent variables (conditions with and without thermomechanical load cycling).

Statistical significant differences were observed between acid etching-treated ceramics (EM and $\mathrm{SV})(\mathrm{P}<.001)$ regarding surface roughness $(\mathrm{Ra}$ in nm) $(631.3 \pm 35.27$ and $550.3 \pm 39.46)$ respectively. Representative SEM micrographs of EM and SV glass ceramic materials at 2000x magnification are presented in Figures 3 (A and B) respectively. The treated EM ceramic surface showed micro-rough and porous surface than did treated SV ceramic surface. The SEM micrographs of EM and SV glass ceramic materials at 5000x showed that EM glass ceramics have needle-shaped, fine-grained crystals embedded in glassy matrix (Fig.4A), whereas SV ceramics have a homogenous fine crystalline structure (Fig. 4B).

TABLE (2) Mean ( \pm standard deviations) flexural strength values (Mpa) of EM and SV glass ceramics with or without thermomechanical load cycling

\begin{tabular}{|c|c|c|c|}
\hline \multirow{2}{*}{$\begin{array}{c}\text { Ceramic } \\
\text { type }\end{array}$} & \multicolumn{2}{|c|}{$\begin{array}{c}\text { Thermo-mechanical load } \\
\text { cycling conditions }\end{array}$} & \multirow{2}{*}{ Total } \\
\cline { 2 - 3 } & Without & With & \\
\hline EM $(\mathrm{X} \pm \mathrm{SD})$ & $383.38 \pm 8.88^{\mathrm{a}}$ & $361.32 \pm 5.47^{\mathrm{b}}$ & $372.35 \pm 13.4$ \\
\hline $\mathrm{SV}(\mathrm{X} \pm \mathrm{SD})$ & $451.35 \pm 9.41^{\mathrm{B}}$ & $439.68 \pm 5.69^{\mathrm{B}}$ & $445.52 \pm 34.35$ \\
\hline$P$-value & $<.001$ & $<.001$ & $<.001$ \\
\hline
\end{tabular}

-Different superscript letters indicate significant difference between thermomechanical cycling conditions for each glass ceramic $(P<.05)$.

-P-value when comparing the two types of ceramic either overall or or between each thermomechanical cycling conditions 


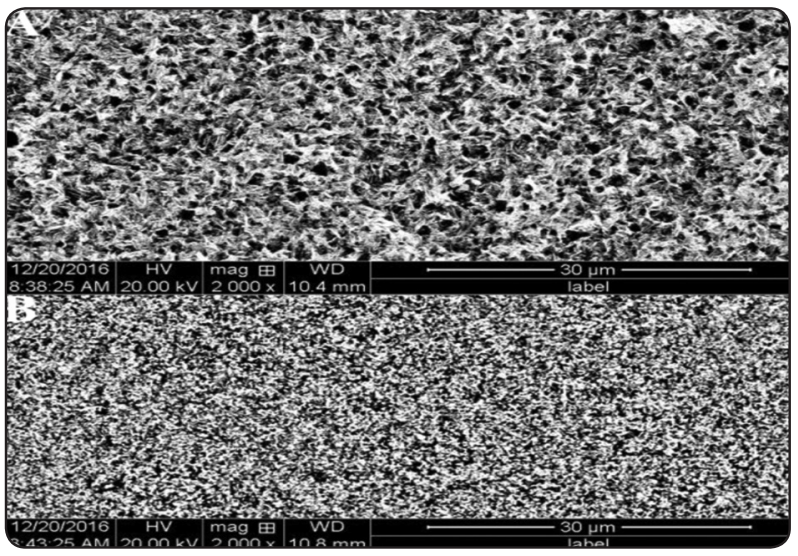

Fig. (3) SEM micrographs after acid etching for $20 \mathrm{~s}$ at $2000 \times$ for A: EM and B: SV glass ceramics

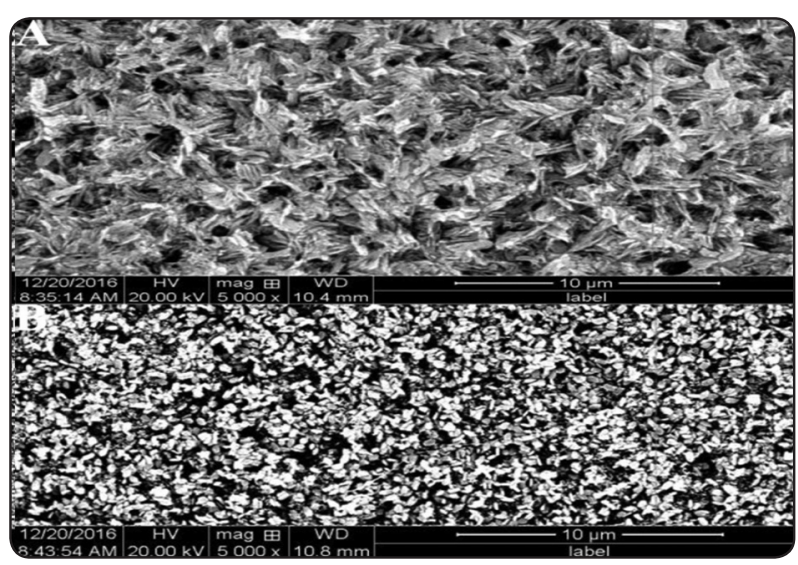

Fig. (4) SEM micrographs after acid etching for $20 \mathrm{~s}$ at $5000 \times$ for A: EM and B: SV glass ceramics

disilicate after applying combined thermomechanical load cycling.

The adhesion of SV and EM glass ceramics was determined in the current study by the $\mu$ TBS test as it distributes stresses uniformly during loading and gives accurate estimation of bond strength because of the presence of small bonded interfaces (approximately $1 \mathrm{~mm}^{2}$ ). ${ }^{28-30} \mathrm{In}$ addition, composite resin disks were used rather than dental substrates because of the strong bond formed between the composite resin and the resin cement. In addition, variations in the tooth microstructure could lead to the misinterpretation of the findings..$^{13}$

The microtensile bond strength values of nonaged EM glass ceramics were significantly higher than those of SV glass ceramics. This could be attributed to the higher surface roughness values caused by the acid etching process. This result also agrees with that observed from the SEM micrographs and surface roughness values of SV glass ceramic in the current study, which showed that etching was more apparently intense for Em glass ceramics. Moreover, these findings are in agreement with the classification system proposed by Valendro et al. ${ }^{31}$, who stated that EM glass ceramics is considered acid-sensitive ceramics, which improves the values of SV glass ceramics with those of lithium and compare the flexural strength and adhesion

further investigations; its composition might have different bonding and mechanical characteristics from those of its predecessor (EM glass ceramics). Therefore, the current study was aimed to evaluate 
formation of mechanical interlocking with luting agent. However, zirconia-based ceramics do not degrade easily with HF acid and are considered resistant to acids. ${ }^{31}$. The small statistical difference between EM and SV glass ceramics regarding bond strength values was not surprising because (monobond plus) coupling agent, which contain phosphate monomer, were used. The presence of zirconia requires this kind of monomer to enhance the chemical bond with the resin adhesive. ${ }^{31,32} \mathrm{On}$ the contrary, another study stated that SV glass ceramics had higher tensile bond strength than EM glass ceramics. ${ }^{33}$ This difference may be because they used a 60-s etching time, which might increase the micropore depth in ceramic surfaces. However, $\mathrm{HF}$ etching time for SV glass ceramics was $20 \mathrm{~s}$, as recommended by the manufacturer. ${ }^{5}$

The microtensile bond strength of EM and SV glass ceramics was significantly reduced after thermo-mechanical load cycling. Temperature variations and mechanical fatigue of dental materials are factors that cause material degradation in aqueous environment, which consequently affects their bond strength. ${ }^{25,34}$ Although the acid etching was more pronounced on EM than on SV glass ceramics, the microtensile bond strength of EM glass ceramics significantly reduced compared with that of SV glass ceramic after thermomechanical load cycling. This could be attributed to the presence of zirconia particles, which could resist aging conditions more than those in EM glass ceramics by transformation toughening process. ${ }^{35}$ Therefore, the first null hypothesis was rejected. Kamada et al ${ }^{36}$ stated that thermocycling reduces the bond strength between a ceramic surface and resin cement. In addition, another study stated that the microtensile bond strength of lithium disilicate ceramics reduced significantly in both the fatigued group and thermocycled group. ${ }^{10}$ On the contrary, other studies showed that the thermal and mechanical cycling did not statistically affect the bond strength of lithium disilicate ceramics. ${ }^{11,37}$
Failure modes analysis in this study revealed that adhesive failure incidence increased in both the types of glass ceramics after the thermomechanical cycling at the expense of the mixed-type failure, with pronounced effect on EM glass ceramic. This observation could be related to the bond strength results and could be attributed to the thermal and mechanical stresses formed during thermocycling and mechanical cyclic fatigue loading in both types of glass ceramics. ${ }^{38}$

Dental ceramics are weak in tension because of their brittle nature. Accordingly, flexural strength is an important mechanical property to predict their strength in clinical situation. ${ }^{39}$ Environmental cycling parameters used to predict the survival rate of glass ceramics vary widely among the studies ${ }^{10,37,38}$ and there is no agreement regarding these parameters in the literatures. Therefore, the accurate simulation of normal functional parameters remains a challenge. The parameters of mechanical and thermal cycling applied in the current study were based on the study of zankuli et.al ${ }^{40}$ and khalil et.al. ${ }^{14}$; They utilize 3500 thermal cycles and 250,000 mechanical loading cycles to simulate one year of clinical service.

SV glass ceramic showed higher flexural strength values than EM glass ceramic both before and after the thermo-mechanical load cycling. The introduction of zirconia particles in SV glass ceramic could improve flexural strength by interrupting the crack propagation. ${ }^{41}$ Therefore; the second null hypothesis was rejected. Moreover, the flexural strength of SV glass ceramic was non-significantly reduced after thermo-mechanical load cycling. The results of this study is supported by other studies outcomes ${ }^{14,42,43}$ which stated that; The effect of thermal and mechanical load cycling did not significantly affect flexural strength of zirconia based ceramics due to their strong mechanical properties and stability against aging. Moreover, stress-induced phase transformation is an important factor for strengthening of zirconia based ceramics. 
On the other hand, grain size is one of the factors that could affect the mechanical properties of dental ceramics. The smaller the grain size, the higher is the mechanical strength for zirconia-based ceramics. The grain size of EM glass ceramics was $2-4 \mu \mathrm{m}$, while that of SV glass ceramics was $0.5-$ $0.7 \mu \mathrm{m} .{ }^{5,26} \mathrm{On}$ the contrary, another study stated that mechanical load and thermal cycling decreased the flexural strength of zirconia-based glass ceramics. ${ }^{44}$ Accordingly, limitations of this in vitro study demand further investigations following prolonged thermo-mechanical load cycling.

\section{CONCLUSION}

Within the limitation of this study, it was concluded that; SV glass ceramic showed higher bonding values than EM glass ceramic after thermomechanical load cycling. However, it provides higher flexural strength values either before or after thermo-mechanical load cycling than EM glass ceramic. From the statistical point of view, the overall bond strength values were not significantly different between both SV and EM glass ceramics regardless of the thermo-mechanical load cycling. Therefore, further clinical investigations are required to predict the bonding durability of $\mathrm{SV}$ glass ceramics in clinical situations.

\section{REFERENCES}

1. Kelly JR and Benetti P. Ceramic materials in dentistry: historical evolution and current practice. Aust Dent J 2011; 56 Suppl 1:84-96.

2. Guess PC, Vagkopoulou T, Zhang Y, et al. Marginal and internal fit of heat pressed versus CAD/CAM fabricated allceramic onlays after exposure to thermo-mechanical fatigue. J Dent 2014; 42: 199-209.

3. Fasbinder DJ. Clinical performance of chairside CAD/ CAM restorations. J Am Dent Assoc 2006; 137:22-31.

4 Niu E, Agustin M, and Douglas RD. Color match of machinable lithium disilicate ceramics: effects of foundation restoration. J Prosthet Dent 2013; 110:501509 .
5. Vita Suprinity CAD/CAM Restorative. Vita Suprinity Brochure. Available at: https://www.vita-zahnfabrik.com/ en/ VITA-SUPRINITY- 9459.html.

6. Callister WD Jr. Failure, In: Materials Science and Engineering: An Introduction, John Wiley \& Sons, New York, NY, 2007, 207-251.

7. Wiskott HW, Nicholls JI, and Belser UC. Stress fatigue: basic principles and prosthodontic implications Int $\mathrm{J}$ Prosthodont 1995; 8(2) 105- 116.

8. Borges GA, Caldas D, Taskonak B, et al. Fracture loads of allceramic crowns under wet and dry fatigue conditions $\mathrm{J}$ Prosthodont 2009; 18(8): 649-655.

9. Krämer N and Frankenberger R. Clinical performance of bonded leucite-reinforced glass ceramic inlays and onlays after eight years. Dent Mater 2005; 21:262-71

10. Guarda GB, Correr AB, Goncalves LS, et al. Effects of surface treatments, thermocycling, and cyclic loading on the bond strength of a resin cement bonded to lithium disilicate glass ceramics. Oper Dent 2013; 38(2):208-217.

11. Sato TP, Anami LC, Melo RM, et al. Effects of surface treatments on the bond strength between resin cement and a new zironia-reinforced lithium silicate ceramic.Oper Dent 2016; 41(2):284-92.

12. De Oyagüe RC, Monticelli F, Toledano M, et al. Influence of surface treatments and resin cement selection on bonding to densely-sintered zirconium-oxide ceramic. Dent Mater 2009; 25:172-179.

13. Gomes AL, Castillo-Oyagüe R, Lynch $\mathrm{CD}$, et al. A. Influence of sandblasting granulometry and resin cement composition on microtensile bond strength to zirconia ceramic for dental prosthetic frameworks. J Dent 2013; 41:31-41.

14. Khalil A and Abdelaziz KM. Bonding values of two contemporary ceramic inlay materials to dentin following simulated aging. J Adv Prosthodont 2015; 7:446-453.

15. Arias V, Ambrosano G, and Pimenta L. Determination of the sample and plot size for microtensile testing. J Dent Res 2006; 22:283-290.

16. Fabianelli A, Pollington S, Papacchini F, et al. The effect of different surface treatments on bond strength between leucite reinforced feldspathic ceramic and composite resin. J Dent 2010; 38:39-43.

17. Chen C, Kleverlaan CJ, and Feilzer AJ. Effect of an experimental zirconia silica coating technique on micro tensile bond strength of zirconia in different priming conditions. Dent Mater 2012; 28:127-134. 
18. Nguyen JF, Migonney V, Ruse ND, et al. Resin composite blocks via high-pressure high-temperature polymerization. Dent Mater 2012; 28:529-534.

19. ISO 6872. Dentistry-Ceramic materials. Switzerland International Organization for Standardization; 2008 available at:http://www.iso.ch/iso/en/prodsservices/ ISOstore/store.html

20. Cesar PF, Yoshimura HN, Júnior WG, et al. Correlation between fracture toughness and leucite contentin dental porcelains. J Dent 2005; 33:721-729.

21. Elsaka S. Effect of surface treatments on the bonding strength of self-adhesive resin cements to zirconia ceramics.Quintessence Inter 2013; 44(6):170-180.

22. Jardel V, Degrange M, Picard B, et al. Correlation of topography to bond strength of etched ceramic. Int $\mathrm{J}$ of Prosthodont 1999; 12(1): 59-64.

23. Critchlow S. Ceramic materials have similar short term survival rates to other materials on posterior teeth. Evid Based Dent 2012; 13:49.

24. Subramanian D, Sivagami G, Sendhilnathan D, et al. Effect of thermocycling on the flexural strength of porcelain laminate veneers. J Conserv Dent 2008; 11:144-149.

25. Posritong S, Borges AL, Chu TM, et al. The impact of hydrofluoric acid etching followed by unfilled resin on the biaxial strength of a glass-ceramic. Dent Mater 2013; 29:281-290.

26. Studart AR, Filser F, Kocher P, et al. In vitro life time of dental ceramics under cyclic loading in water. Biomaterials 2007; 28:2695-2705.

27. Gilbert JL, Covey DA, and Lautenschlager EP. Bond characteristics of porcelain fused to milled titanium. Dent Mater 1994; 10: 134-140.

28. Amaral R, Özcan M, Bottino MA, et al. Microtensile bond strength of a resin cement to glass infiltrated zirconiareinforced ceramic: the effect of surface conditioning. Dent Mater 2006; 22:283-290.

29. Blatz MB, Sadan A, and Kern M. Resin-ceramic bonding: a review of the literature. J Prosthet Dent 2003; 89:268274.

30. El Zohairy AA, De Gee AJ, Mohsen MM, et al. Microtensile bond strength testing of luting cements to prefabricated CAD/CAM ceramic and composite blocks. Dent Mater 2003; 19:575-583.

31. Valandro LF, Della Bona A, Bottino MA, et al. The effect of ceramic surface treatment on bonding to densely sintered alumina ceramic J Prosthet Dent 2005; 93(3): 253-259.
32. Aboushelib MN and Sleem D. Microtensile bond strength of lithium disilicate ceramics to resin cement.Quintessence inter 2014; 16(6):547-552.

33. Tian $\mathrm{T}$ Aspects of adhesion between CAD/CAM ceramics and resin cements. (Thesis). University of Hong Kong, Pokfulam, Hong Kong SAR 2016, Retrieved from http:// dx.doi.org/10.5353/th_b5760947.

34. Teoh SH. Fatigue of biomaterials: a review. Int Biomat Fatigue 2000; 22: 825-837.

35. Gupta TK, Lange FF, and Bechtold JH. Effect of stressinduced phase transformation on the properties of polycrystalline zirconia containing metastable tetragonal phase. J Mater Sci 1978; 13:1464-70.

36. Kamada K, Yoshida M and Atsuta M. Effect of ceramic treatments on the bond of four resin luting agents to a ceramic material. J Prosthet Dent 1998; 79(5):508-513.

37. Triandade FZ, Kleverlaan CJ, Silva LH, et al. Ceramic inlays: Effect of mechanical cycling and ceramic type on restoration-dentin bond strength. Oper Dent 2016; 41(4):102-117.

38. Saavedra G, Ariki EK, Federico CD, et al. Effect of acid neutralization and mechanical cycling on the microtensile bond strength of glass-ceramic inlays. Oper Dent 2009; 34(2): 211-216.

39. Della Bona A, Anusavice KJ, and DeHoff PH. Weibull analysis andflexural strength of hot-pressed core and veneered ceramicstructures. Dent Mater 2003; 19:662669.

40. Zankuli MA, Silikas N and Devlin H.The effect of cyclic loading on compressive strength of core build-up materials J prosthodont 2015; 24:549-552.

41. Elsaka SE and Elnaghy AM. Mechanical properties of zirconia reinforced lithium silicate glass-ceramic. Dental Mater 2016:32:908-9014.

42. Yilmaz H, Nemli SK, Aydin C, et al. Effect of fatigue on biaxial flexural strength of bilayered porcelain/zirconia (Y-TZP) dental ceramics. Dent Mater 2011; 27:786-795.

43. Güngör MB, Yilmaz H, Aydin C, et al. Biaxial flexural strength and phase transformation of Ce-TZP/A12 O3 and Y-TZP core materials after thermocycling and mechanical loading. J Adv Prosthodont 2014; 6:224-232.

44. Att W, Grigoriadou M, and Strub JR. ZrO2 three-unit fixed partial dentures: comparison of failure load before and after exposure to mastication simulator. J Oral Rehabil 2007; 34: 282-290. 